\title{
The EarthBox Project in Grayson County, Virginia
}

\author{
Kathy Cole ${ }^{a *}$ \\ Grayson LandCare \\ Liza D obson ${ }^{b}$ \\ Virginia Tech
}

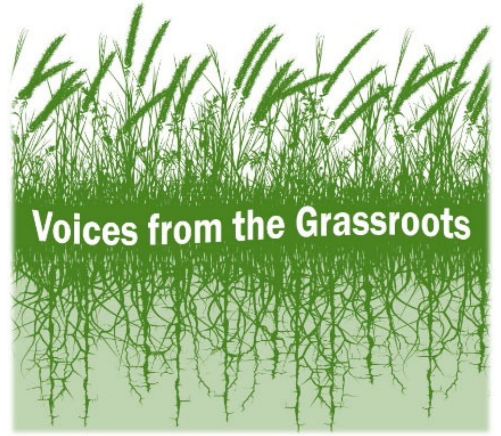

Submitted November 27, 2018/ Published online March 16, 2019

Citation: Cole, K., \& D obson, L. (2019). The EarthBox Project in Grayson County,

Virginia. Journal of A griculture, Food Systems, and Community D evelopment, 8(4), 25-27.

https:/ / doi.org/ 10.5304/ jafscd.2019.084.004

Copyright @ 2019 by the Authors. Published by the Lyson Center for Civic Agriculture and Food Systems. Open access under CC-BY license.

$\mathrm{I}_{\mathrm{s}}^{\mathrm{n}}$ n 2014, Kathy was contacted by Michelle Stamper, coordinator of the local Feeding America mobile pantry program in western G rayson County, Virginia. This pantry serves clients one Monday evening a month at a local school. Feeding America Southwest Virginia sends a truckload of food from Abingdon, Virginia, and volunteers assemble food boxes that are then placed directly in clients' vehicles. Michelle had considered why the food pantry was needed, when rural $\mathrm{G}$ rayson County has such a rich agricultural

a * Corresponding author: Kathy Cole is the president of Grayson LandCare, Inc., in Independence, Virginia (https:/ / grayson landcare.org). This 501(c)(3) nonprofit works to support the economy, environment, and community of Grayson County and surrounding areas. She partnered with Feeding America Southwest Virginia (http:/ / faswva.org) on the EarthBox ${ }^{\circledR}$ project described here. Kathy was born in Grayson County and graduated from Galax High School and Emory \& Henry College. She went on to earn a Ph.D. and spent 30 years with the D epartment of Veterans Affairs before retiring back home to garden, enjoy nature and help her community. She can be reached at +1-276-266-1303 or kathycole1@ live.com. history. When she reached out to Kathy, she asked if the nonprofit Kathy leads, G rayson LandCare, could help her teach pantry clients how to grow some of their own food. She said that many of them grew up with gardening, perhaps at their grandparents' home, but very few gardened currently and some may not even have known how to grow vegetables on their own.

After collecting some information about pantry clients via a short survey, Michelle and

b Liza D obson was a master's student at Virginia Tech at the time of the EarthBox Project, supporting the second year of implementation and conducting an impact evaluation for her thesis (https:/ / vtechworks.lib.vt.edu/ handle/ 10919/ 71672). Liza was born and raised in Maysville, Kentucky, and moved to Blacksburg, Virginia, to study mathematics and environmental engineering at Virginia Tech. After working for two years coordinating school and home gardening projects, she pursued a graduate degree studying gardening projects as a form of rural food security. She then worked two years for the Virginia SNAP-Ed program designing and coordinating a statewide healthy retail program. She can be reached at +1-606-407-1501 or erdobson7@ gmail.com. 
Kathy discovered that many clients were elderly and probably not physically able to garden. Talking with staff at another nonprofit that had previously experimented with planting gardens for the elderly, we learned of the enormous amount of volunteer labor that was needed to construct appropriate inground gardens. A nother barrier we discovered was that some recipients were renters and did not own land. Therefore, in-ground gardens would not be feasible. This led us to consider container gardens, as they could be kept on porches, steps, and even tables.

As Michelle and Kathy were thinking about funding to start the program, Virginia Tech's Appalachian Foodshed Project sent out a request for proposals (RFP) for small food-security projects. Grayson LandCare applied and was granted a few thousand dollars to purchase containers, potting soil, fertilizer, and seeds. We decided to focus on bush green beans because they grow very well here with almost no pests or diseases. Furthermore, green beans are a common and well-liked food in our area.

In researching container gardens for pantry clients, we found the Cadillac of garden containers, the EarthBox ${ }^{\circledR}$. This was specifically created for tomatoes, but being designed with deep soil, it is suitable for almost any garden crop. After the grant was awarded to our project, we called the small company that manufactures EarthBoxes. Happily, it offered us a significant discount because of the nature of our project. With a plan for moving forward, Michelle handed out applications to pantry clients. We had resources for 50 families, and we prioritized families with children. Once the families were identified, they were invited to come to the pantry location on a Saturday afternoon to pick up their boxes and seeds.

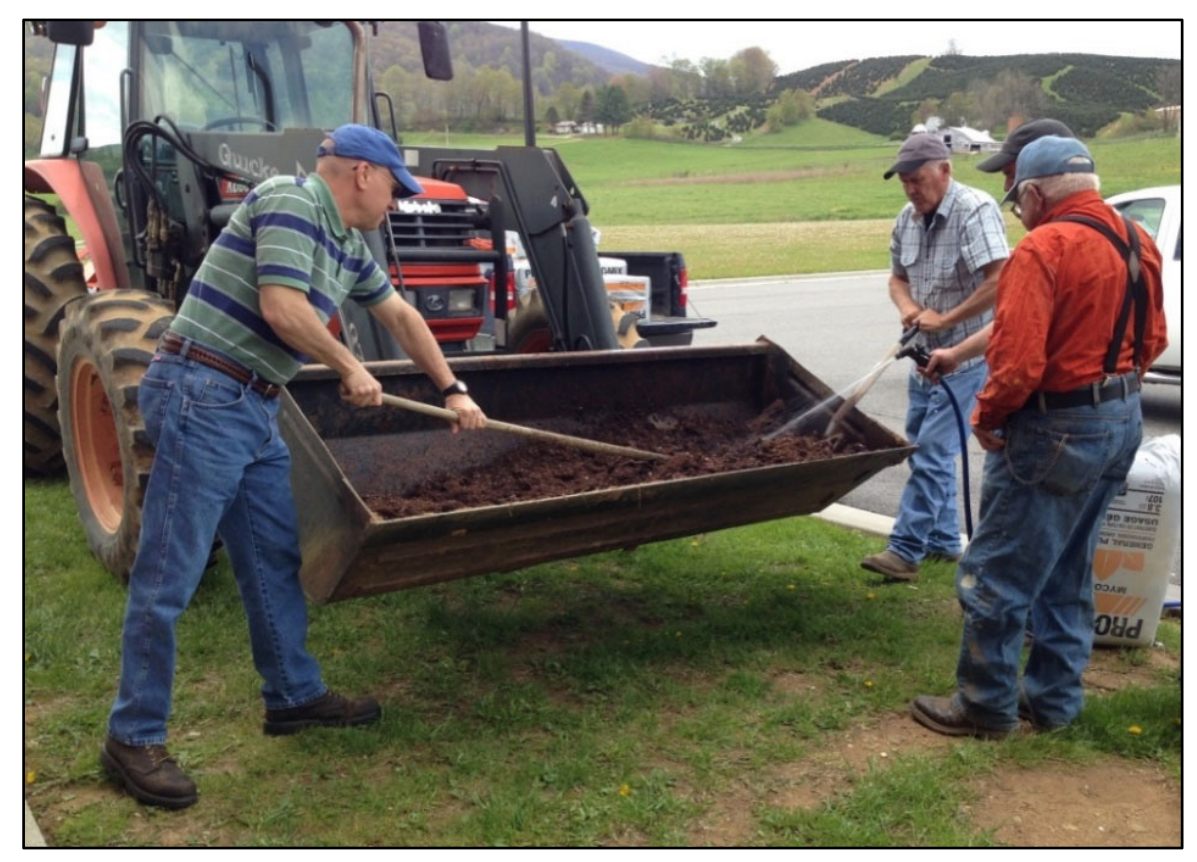

Volunteers help Michelle's father combine the potting mix with water to refresh the EarthBoxes in 2015. (Photo by Kathy Cole.) 


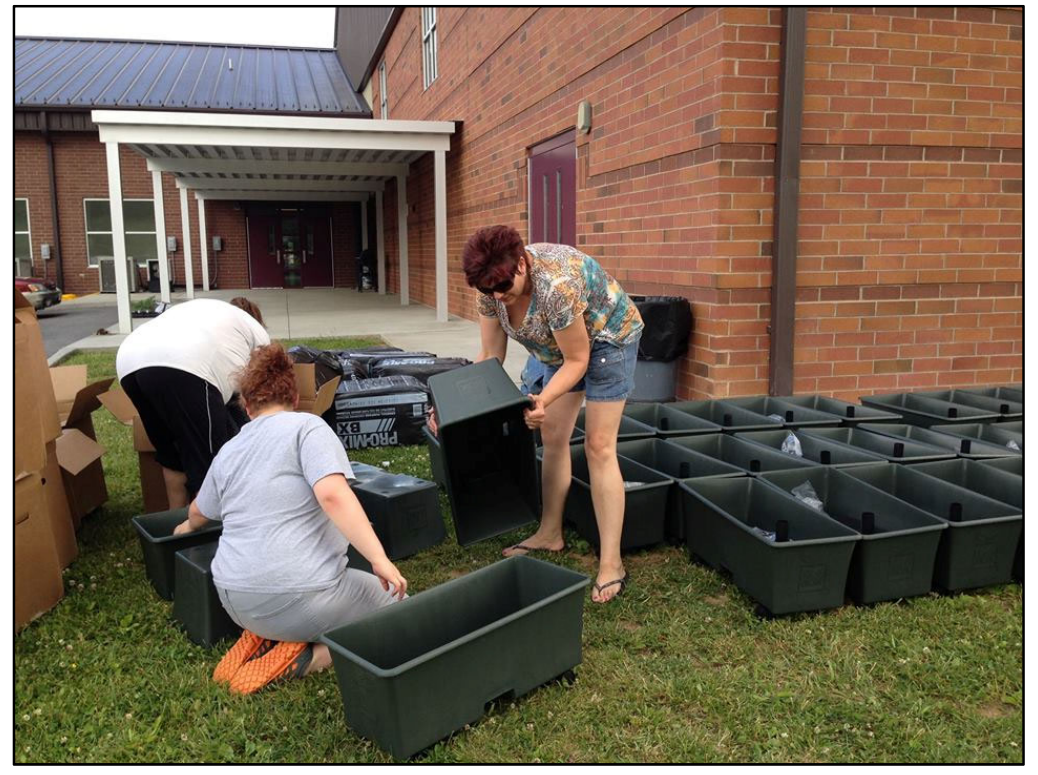

Three volunteers figure out how to assemble 50 EarthBoxes. This was shortly before a downpour began! (Photo by Kathy Cole.)

Kathy recalled two things about that afternoon: (1) the jet fighters on a training mission that came over the school with a deafening roar, and (2) the cloudburst that had us scrambling to move 50 EarthBoxes and lots of soil to a covered porch onsite. As clients arrived, they helped us assemble EarthBoxes, mix the bags of dry potting soil with water on a large tarp (the kids loved doing this!), fill the EarthBoxes with the moistened soil, plant the beans, and put the little elastic caps on the EarthBoxes. Off they went, in car trunks or truck beds, to their new homes.

Michelle was our link to what was happening, as she saw the clients once a month. O ne family was so delighted with their mother's enthusiasm that they bought her three more EarthBoxes! O ne had a failure with the beans and planted tomatoes, with great success. A few had problems with wildlife eating the produce, even on porches. We lost touch with a few families, too. Although a few folks had challenges, most reported that their beans were growing well! Michelle surveyed the group and most said they had cooked the beans "for supper," what the evening meal is called here. One or two clients had actually canned some of the beans. We were surprised that the EarthBox produced enough beans at one time to can!

The following spring, we had extra funding and offered to refresh the EarthBoxes with new soil, fertilizer, and materials for additional container gardens. To inspire creativity, we suggested that folks use the old soil (now high in nitrogen, thanks to the green beans) to grow potatoes or tomatoes in food-grade buckets we purchased. Again, Michelle invited the same families to the local school on the first Sunday in May 2015. This time, we served lunch, courtesy of her church, in addition to providing the new materials. Everyone got a bucket with holes drilled in the bottom, seed potatoes, fresh soil for the EarthBox, and an aluminum pan of soil to plant shallow-rooted vegetables such as lettuce and radishes. Liza, a graduate student at Virginia Tech supporting and evaluating the project for her thesis, gathered tomato starts and other plants from Virginia Tech and other local farms to hand out that day as well.

We had a wonderful day together, mixing potting mix with water in a front-end loader, drilling holes in buckets, and planting containers for the second season. There is something about getting your hands dirty together that promotes goodwill and friendship.

Liza was able to volunteer at the monthly distributions throughout 2015 to continue handing out seeds and starts to pantry clients before interviewing some folks for her thesis in the fall. We wish we had had more opportunities to meet with the gardeners throughout the project. As people are so scattered here, we only visited a few homes in May 2016 to offer extra plants and resources. If we had been able to stay more connected, we could have customized the project to better fit the needs and wishes of the clients discovered through Liza's research. Container gardening does work well because the containers can be moved if the people have to move, and they are easy to manage for people with limited mobility, such as elderly or disabled people. And nobody doesn't like green beans! 